\title{
Uma leitura epistemológica de Sobre o conceito de história de Walter Benjamin
}

\section{Anna Luiza Coli (UFMG)}

Resumo: O objetivo deste artigo é mostrar que, em primeiro lugar, o interesse de Walter Benjamin pela questão da história já estava presente em seus escritos de juventude, desde então aliado a uma investigação essencialmente epistemológica. Em segundo lugar, portanto, pretende-se evidenciar de que modo esta epistemologia de juventude nos ajuda a compreender o texto final Sobre o conceito de história, destacando a rememoração (Eingedenken) como conceito-chave desta possível aproximação.

Palavras-chave: reflexão, origem, rememoração.

Entender o pensamento de WB é entender o percurso de problemas e inquietações que desde muito cedo marcaram as posições teóricas do jovem estudante que aos 20 anos já estava à frente do movimento de juventude de Berlim. Exatamente por isso, o que proponho aqui é uma breve reconstrução dos passos decisivos que levaram WB, por um lado, às formulações epistemológicas do Prefácio de Origem do drama barroco alemão, publicado em 1928, apesar dos esboços mais antigos datarem de 1916 e, por outro lado, às enigmáticas teses Sobre o conceito de história, escritas no ano de sua morte, em 1940.

O primeiro passo que daremos junto ao jovem WB nos remete ao início da década de 1910 quando, na Universidade de Freiburg, ele frequenta as aulas do proeminente neokantiano Heinrich Rickert - que tinha também como aluno Martin Heidegger, apenas três anos mais velho que WB - e ao ano de 1918 quando, depois de dedicar-se à leitura intensa de Kant ${ }^{1}$, entra em contato com a importante obra de outro famoso neokantiano, Kants Theorie der Erfahrung de Hermann Cohen. Data deste mesmo ano o texto Sobre o programa da filosofia vindoura, em que, sem deixar de lado uma postura de reverência frente ao esforço sistemático de Kant e à preocupação com a justificação do conhecimento, ele se concentra na crítica ao tratamento reducionista que Kant teria dado ao conceito de experiência. WB situou o problema da experiência no centro do que chamou de o "fracasso da filosofia kantiana" ${ }^{2}$, por um lado, em fundar a validade do conhecimento sobre a estrutura de uma experiência expurgada de todo traço metafísico e, por outro, em justamente querer extirpar a metafísica de seu edifício teórico quando, na visão de WB, a concepção de um "eu corpóreo e individual que recebe as impressões mediante os sentidos e que, tomando-as como base forma suas representações" ${ }^{3}$ não escapa à mitologia e, "quanto ao seu conteúdo de verdade, não é mais valiosa que qualquer outra mitologia do conhecimento." ${ }^{4} \mathrm{O}$ que nos é importante nesse fôlego inicial do pensamento de WB são dois aspectos que aparecem já em 1918 e que a partir de então ganham corpo e se fortalecem ainda mais no diálogo com o romantismo de Iena e Goethe, a saber, em primeiro lugar, a necessidade de superar o que ele caracterizou como "falsa disjunção" de sujeito-objeto, segundo a qual "o conhecimento está ou na consciência de um sujeito cognoscente ou no objeto" 5 , no intuito de recuperar para a

Cadernos Benjaminianos, n. 3, Belo Horizonte, jan.-jun. 2011, p.14-25 
experiência o campo de "total neutralidade em relação aos conceitos de objeto e sujeito" ${ }^{6}$ e, assim, sua dimensão propriamente significativa; e, em segundo lugar e como consequência do primeiro, a necessidade de redefinir as bases do conhecimento que possa se valer de uma nova estrutura da experiência.

É nesse momento que passamos à consideração do diálogo que WB estabeleceu com os românticos de Iena, dentre os quais se destaca a figura de Schlegel, na ocasião da redação de sua tese de doutorado, escrita em 1919 e publicada como Sobre o conceito de crítica de arte no romantismo alemão. É bastante relevante para nossos propósitos aqui lembrar que esta tese, a princípio, seria dedicada a Kant e teria como tema a 'tarefa infinita'. Em virtude da decepção que WB teve justamente com o seu conceito de experiência, no entanto, o projeto da tese foi substituído pelo estudo do conceito romântico de crítica, no qual ele demonstraria que "a estética de Kant é um pressuposto essencial da crítica de arte romântica". Aos poucos, como se pode ler nas correspondências, WB abandona a relação entre Kant e os românticos para dedicar-se somente a estes e, numa carta de novembro de 1918, escreve: "O que apreendo através dela [a tese], a saber, um olhar na relação de uma verdade com a história, será, no entanto, pouco discutido no trabalho, mas, eu espero, será percebido pelos leitores perspicazes." ${ }^{\circ}$

Seguindo a pista que WB nos deixa nesta carta, proponho abordar sua leitura dos românticos sob o prisma desse contratempo com a filosofia kantiana, no sentido de que ele buscou na obra dos românticos o que havia então buscado, sem sucesso, em Kant. Proponho aqui, portanto, uma análise dessa obra a partir do problema da relação entre o conhecimento e a experiência que, entretanto, somente no prefácio à obra sobre o drama trágico alemão (Trauerspielbuch, 1928) toma definitivamente a forma do problema entre a verdade e a história, tal como ele, provocativamente, escreve em 1918.

\section{O projeto epistemológico}

Tendo em vista a importância da questão do conhecimento para WB à época da redação de sua tese, propõe-se aqui uma abordagem da obra $O$ conceito de crítica de arte no romantismo alemão menos como um estudo acadêmico sobre a obra de Schlegel e dos românticos de Iena e mais como uma expressão de suas próprias formulações epistemológicas, em que o debate com Kant persiste, embora travestido no esforço de buscar a influência da estética kantiana no pensamento romântico. Com efeito, WB localizou o conceito de reflexão no centro da exposição não somente da crítica como também da teoria do conhecimento românticas, essencialmente conectadas pelo fato de que "a crítica não pode ser pensada sem pressupostos gnosiológicos [...] porque contém um momento de conhecimento". 9

A reflexão romântica aparece sob a pena de WB como a atividade do pensamento que, ao voltar-se sobre sua forma para torná-la seu conteúdo - o pensar da forma do pensar desencadeia um processo de autoconhecimento infinito através do qual se alcança o conhecimento do mundo. O fenômeno do qual partem os românticos é o simples pensar a si mesmo e, na medida em que há uma unificação entre o pensamento do Eu e o mundo, o conhecimento é tratado como uma atividade do sujeito sobre si mesmo e não sobre um objeto que lhe é estranho, alheio. O germe do conhecimento do mundo se encontra na reflexão infinita e, portanto, na si-mesmidade e no autoconhecimento. WB chega mesmo a dizer: "Como é possível conhecimento fora do autoconhecimento, i.e., como é possível conhecimento do objeto? Ele de fato não é possível."10

Cadernos Benjaminianos, n. 3, Belo Horizonte, jan.-jun. 2011, p.14-25 
Onde o pensamento do Eu não está unificado com o conceito de mundo, podese dizer que este pensar puro do pensamento do Eu só conduz a um eterno espelhar-se-a-si-mesmo, a uma série infinita de imagens-reflexo que contém sempre o mesmo e nunca algo novo. [...] Auto-intuição e intuição do universo são conceitos intercambiáveis. ${ }^{11}$

A reflexão é, assim, guiada pela tarefa de descobrir o conhecimento do mundo no autoconhecimento, bem como o autoconhecimento no conhecimento do mundo. E nesse processo um passo bastante importante é dado: a experiência do eu é dada ao mesmo tempo que a experiência do mundo, e poderíamos mesmo dizer que elas se referem a um e mesmo conteúdo. ${ }^{12}$ A experiência do mundo é, dessa forma, arrastada para o âmbito singularíssimo do Eu e da experiência de si numa espécie de abolição da diferença exterior-interior, mundo-sujeito ou, na terminologia de WB, de "superação da distinção sujeito-objeto". ${ }^{13}$ Mas como essa unificação entre eu e mundo pode ser entendida? Se nesse ponto voltarmos à afirmação de WB segundo a qual o pressuposto essencial da teoria romântica do conhecimento era dado pela estética kantiana e pelo conceito de reflexão, podemos buscar aí uma afinidade que nos é essencial: a reflexão surge no contexto da Crítica da Faculdade de Julgar como expressão da relação que o sujeito estabelece consigo mesmo, i.e., com suas faculdades de conhecimento, perante a representação do objeto. Essa relação não diz nada do próprio objeto e não produz, dessa forma, nenhum conhecimento. ${ }^{14}$ No entanto, expressa uma interação entre o sujeito e a representação do objeto referida apenas ao sujeito, ou ao seu sentimento (de prazer ou desprazer) diante do objeto. O conceito de reflexão surge, assim, como a possibilidade de pensar esse campo de "total neutralidade" em que a dicotomia sujeito-objeto deixa de fazer sentido ao considerá-los partes inseparáveis de uma mesma experiência do mundo que é também experiência de si mesmo no mundo. Assim apropriada pelos românticos, é essencialmente sobre essa concepção de reflexão que WB vai tentar resgatar para o conhecimento uma experiência efetiva, ou melhor, significativa e singularíssima do mundo.

A contrapartida de fundar um conhecimento sobre a base de uma experiência significativa e singular - em contraste com a experiência universalizável do conhecimento para Kant - é a imposição do seu caráter de radical individualidade. E então cabe a pergunta: como estabelecer um conhecimento significativo do mundo a partir da experiência de um único eu? E nesse ponto a resposta de WB, falando em nome dos românticos, antecipa de forma surpreendente o argumento central do Prefácio à obra Origem do drama barroco alemão: a reflexão deve assumir, portanto, uma dinâmica infinita "não uma infinitude da continuidade, mas uma infinitude da conexão [...] [em que] tudo se conecta de uma infinita multiplicidade de maneiras" $" 15$, em que cada experiência singular é tomada como um fragmento da realidade que adquire sentido no interior de uma constelação de outros fragmentos que se agrupam, se dissipam, e se reagrupam na possibilidade infinita do conectar e, portanto, de relacionar infinitamente os fragmentos e buscar incansavelmente os estratos de significados disponíveis. ${ }^{16}$ "Experiência é a multiplicidade unitária e contínua do conhecimento". ${ }^{17}$

Nesse ponto, é necessário ressaltar ainda um importante momento desse diálogo, em que WB encontra um pano de fundo marcadamente místico por trás da teoria do conhecimento romântica, e que, curiosamente, guarda uma profunda semelhança com as

Cadernos Benjaminianos, n. 3, Belo Horizonte, jan.-jun. 2011, p.14-25 
ideias centrais de seu texto Sobre a linguagem em geral e a linguagem dos homens, ${ }^{18}$ que data da mesma época da redação da tese, e que é até mesmo considerado por alguns comentadores $^{19}$ como texto-apêndice a ela. Este flerte com uma terminologia mística, mais evidente no âmbito da teoria romântica da tradução e de uma concepção do mundo

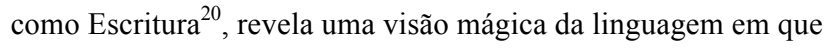

a linguagem original relacionava o homem diretamente com um conhecimento total e com a natureza. A queda equivale ao início da 'confusão', do caos, da não-compreensão $\mathrm{e}$, portanto, da necessidade de se interpretar - e traduzir - o mundo e as palavras. ${ }^{21}$

A ideia subjacente a todo o esforço infinito do procedimento reflexivo de buscar restaurar a máxima significação das coisas pela possibilidade infinita de conexões poderia ser dita, portanto, como sendo a de se aproximar de um ideal de compreensão do mundo que foi absolutamente interditado ao pensamento quando da Queda. Essa seria a linguagem originária sobre a qual os românticos sempre se voltam, e a reconquista desse acesso direto à essência da coisa e, mais que isso, a recuperação da harmonia entre homem e mundo, seria o grande ponto motivador para o estabelecimento disso que os românticos chamam de "linguagem artificial/artística". ${ }^{22}$ Ela é necessária porque a linguagem natural, cujo uso é meramente comunicativo, representa uma linguagem decaída, parcial, imperfeita e, por isso, deve ser superada por uma linguagem artificial/artística capaz de reconquistar para o conhecimento a essencialidade do mundo que foi perdida juntamente com a linguagem originária ou, como o diz WB, "adâmica" ${ }^{23}$ O essencial desta concepção do conhecimento como restauração do acesso ao núcleo significativo do mundo, possível apenas pelo estabelecimento de uma linguagem artificial, pode ser apontado como a consciência de que a única relação que nos resta com a verdade é inteiramente dependente de um esforço de construção do mundo como objeto de conhecimento verdadeiro, essencialmente distinto do mundo como mero objeto da percepção. Há uma consciência aguda de que a verdade não é dada imediatamente no mundo - não mais - mas deve ser buscada num esforço infinito e incansável de restauração, de reabilitação e principalmente de construção de uma dimensão verdadeiramente significativa. Nessa reconstrução, que forma uma espécie de duplocontrário da fragmentação, surge o conceito de absoluto.

Sob o olhar de WB, o absoluto romântico aparece como o lócus da ação da reflexão, como o palco em que as essências fragmentadas são dispostas de forma completamente livre para estabelecerem infinitas conexões. Nesse sentido, o absoluto configura um medium-de-reflexão, ou seja, ele é o meio em que toda espécie de regra associativa é suspensa a favor de um processo fortuito e desordenado de conexões. Só pode ser restaurado aquilo que foi destruído. Assim, o absoluto é o meio em que tudo aquilo que foi desmembrado e dissolvido pela ação da reflexão pode se aproximar da restauração de sua significação originária e verdadeira. O grande alcance do conceito de absoluto para o pensamento de WB, portanto, pode ser obtido, em primeiro lugar, na possibilidade de se pensar uma instância que permita à filosofia um curso intermitente, cíclico, casual, no qual a reflexão possa surgir de um ponto qualquer, indiferenciado, e assim se dirigir para outro igualmente indeterminado. $\mathrm{O}$ absoluto como medium-de-reflexão permite ao pensamento um movimento contínuo e infindável que, ao contrário das filosofias que buscam no conceito seu termo, sua conclusão, refaz o seu movimento infinitas vezes e de

Cadernos Benjaminianos, n. 3, Belo Horizonte, jan.-jun. 2011, p.14-25 
formas as mais variadas. Em suma, o conceito de absoluto preserva a possibilidade de que a filosofia seja "apresentação da verdade", tal como WB prescreve nas primeiras linhas do Prefácio. Como diz exemplarmente Gagnebin,

insistir sobre a expressão em linguagem da filosofia acarreta também, no Prefácio ao livro sobre o drama barroco, uma separação nítida entre dois aspectos, geralmente unidos ou confundidos, do pensamento filosófico: filosofia como conhecimento (Erkenntnis) e filosofia como apresentação (Darstellung) da verdade. [...] O conhecimento científico que se orienta pelo modelo matemático e geométrico e que deveria, segundo a tradição cartesiana, também servir de paradigma à filosofia, esse conhecimento se caracteriza pelo ideal de "eliminação do problema da apresentação". ${ }^{24}$

Em segundo lugar, no entanto, na concepção sistemática desenvolvida na Athenäum $^{25}$ em que a arte figura como o medium-de-reflexão absoluto, o absoluto que tem na arte o seu meio poderia muito bem ser corporificado como história. Segundo o próprio Schlegel, "a arte, criada a partir do impulso da aspiração da espiritualidade, conecta esta em formas sempre novas com o acontecer do conjunto da vida do presente e do passado. A arte liga-se não a acontecimentos singulares da história, mas a sua totalidade" ${ }^{26}$ Nesse sentido, o absoluto, enquanto medium que abarca sob si a totalidade das conexões, representa a possibilidade de que algo acontecido no momento presente se conecte livremente a algum evento passado e, portanto, que a ressignificação advinda dessa ligação adquira uma importância histórica que poderia, eventualmente, ser representada na conexão entre a França revolucionária de Robespierre e a Roma Antiga. E nesse ponto chegamos, finalmente, à nossa meta: no estudo sobre o romantismo podemos apreender de que modo a conexão infinita e indeterminada nos coloca em um local de suspensão de toda e qualquer legislação exterior à relação entre eu e mundo, e portanto, nessa busca de significação absolutamente livre - inclusive de amarras temporais -, podemos estabelecer com o tempo uma relação igualmente desprendida da lógica linear do curso da história, na qual a verdade se apresenta. 


\section{O conceito de Origem}

Com efeito, poderíamos dizer que essa relação entre uma verdade e a história antecipa a formulação que WB dá ao conceito de Origem no Prefácio. A Origem surge como uma espécie de ponto de chegada do método próprio da escrita filosófica - a apresentação da verdade -, ao mesmo tempo em que resguarda sua estrutura essencialmente histórica não como retorno arcaicizante ao momento histórico da gênese mas como categoria que é fundada na cristalização de um instante histórico. A adequada compreensão da origem exige, todavia, uma breve menção ao contexto que ela surge no Prefácio.

Estabelecendo uma diferença fundamental entre conhecimento (Erkenntnis) e verdade (Wahrheit), para a qual "as instâncias do conhecimento [...] não são nem partes nem fragmentos da verdade e por isso mesmo não compartilham sua natureza", ${ }^{27}$ WB afirma que, por terem caráteres distintos, "conhecimento e verdade nunca são idênticos" e, dessa forma, "não há conhecimento verdadeiro nem verdade conhecida". ${ }^{28}$ Com efeito, o conhecimento surge no Prefácio como o objeto de que a consciência de um sujeito deve se apossar e que, ao eliminar o problema da apresentação, renuncia no mesmo ato à esfera da verdade. "É próprio da literatura filosófica", no entanto, "o ter de confrontar-se a cada passo com a questão da apresentação". Assim, prossegue WB, "se a apresentação se quiser afirmar como o método próprio do tratado filosófico, terá de ser apresentação das ideias. A verdade, presentificada no bailado das ideias apresentadas, furta-se a toda e qualquer projeção no domínio do conhecimento". ${ }^{29}$ A terminologia aqui empregada por WB, embora espelhe intencionalmente a estabelecida por Kant (fenômeno, conceito e ideia), tem uma significação e uma dinâmica inteiramente diferentes, exigindo cuidado redobrado do leitor. Dito isso, passemos ao método:

Em sua existência empírica, os fenômenos não podem ser imediatamente transpostos para o reino das ideias, mas, antes, precisam primeiramente sofrer a ação destruidora dos conceitos. Ao implodir e transformar o fenômeno em um amontoado de elementos constitutivos dispersos, os conceitos conseguem abrigar os fenômenos sob as ideias, "pois as ideias não se apresentam em si mesmas, mas apenas e exclusivamente através de uma organização dos elementos coisais no conceito. ${ }^{30} \mathrm{O}$ móbil dessa apresentação da verdade como caminho não-direto, como pensamento que volta continuamente ao princípio, parece guardar uma intenção surpreendentemente similar àquela da reflexão romântica: desmontar a totalidade aparente das coisas para que elas, dispersas e desordenadas em seus elementos constitutivos, possam estabelecer livremente infinitas conexões, e buscar as infinitas significações possíveis do objeto como sua verdade. Nesse sentido a comparação com o mosaico é bastante elucidativa:

A relação entre a elaboração micrológica e a escala do todo, de um ponto de vista plástico e mental, demonstra que o conteúdo de verdade (Wahrheitsgehalt) se deixa apreender apenas através da mais exata descida ao nível dos pormenores de um conteúdo material (Sachgehalt). ${ }^{31}$

As ideias são, assim, uma espécie de constelação em meio à qual gravita, na forma de estrelas, o fenômeno fragmentado em múltiplos elementos. "A estrutura da verdade exige um modo de ser que, na sua ausência de intenção, se aproxima do modo de ser simples das coisas, mas lhes é superior pela sua consistência e permanência." 32

Cadernos Benjaminianos, n. 3, Belo Horizonte, jan.-jun. 2011, p.14-25 
Nesse ponto cabe perguntar: uma vez que a verdade é apresentação do mundo no reino das ideias, onde se encaixa, então, a origem? E a resposta é clara: a origem é o confronto da verdade apresentada pelas ideias com a história, i.e., "o fenômeno originário é a atualização da ideia exposta como virtualidade" ${ }^{, 3}$ no sentido de que ela (a origem) atualiza as virtualidades do mundo e dos fenômenos sempre em relação à história. A origem expressa a relação de uma verdade com a história.

Enquanto categoria estrutural, a origem cristaliza o momento da gênese e absorve a configuração histórica da mesma forma como "o recém-nascido pode ser concebido [...] em um estado de perfeita adequação à configuração atual do cosmo." ${ }^{34}$ Nesse sentido, a origem atua como um ponto de imantação em torno do qual gravita todo o material produzido pela gênese na forma de virtualidades, ou seja, de propriedades passíveis de atualização a cada vez que uma ideia se apresenta confrontada com a história. ${ }^{35}$

Em todo fenômeno originário tem lugar a determinação da figura através da qual uma ideia permanentemente se confronta com o mundo histórico, até atingir a completude na totalidade da sua história. A origem, portanto, não se destaca dos dados factuais, mas tem a ver com a sua história anterior e posterior. $^{36}$

Enquanto instância que cristaliza as determinações dos fenômenos em face do momento histórico singularíssimo de sua gênese, a origem é restauração, reestabelecimento do significado preciso de sua criação. No entanto, justamente por abrigar todas as determinações dos fenômenos como virtualidades, a origem envolve ainda uma experiência de alteração e criação do novo que é próprio do que permanece inacabado. "O movimento da origem só pode ser reconhecido, 'por um lado, como restauração e reprodução, e por outro lado, e por isso mesmo, como incompleto e inacabado' (não fechado)". ${ }^{37}$ Esta abertura para o novo e para o diferente é sua abertura para o futuro, para os novos confrontos que o fenômeno pode, sempre de novo, estabelecer com a história. E esse é o sentido monadológico da ideia, em que tanto a história anterior quanto a posterior do fenômeno estão contidas, embora como virtualidades que jamais alcançarão sua atualização plena, nas possibilidades infinitas de atualização das ideias. A ideia como mônada consagra a coincidência entre o singular e o universal na medida em que concentra história e temporalidade no fenômeno.

Origem, enteléquia, mônada: trata-se sempre da mesma ideia de totalização a partir do próprio objeto e nele, da referência a uma história anterior e posterior irredutíveis ao desenvolvimento cronológico da Entstehung [gênese]. ${ }^{38}$

Assim, ao mesmo tempo em que a origem visa essa dimensão de totalização do objeto, por ser abertura e inacabamento, ela "também testemunha a não realização da totalidade. Ela é ao mesmo tempo indício da totalidade e marca notória da sua falta". ${ }^{39}$ É por isso, diz WB, que não existem encontros imediatos com o passado, bem como não se pode estabelecer uma verdade indiscutível e exaustiva para a história, uma vez que a "verdade histórica não é da ordem da verificação factual". ${ }^{40}$ A verdadeira relação com o passado, portanto, só pode ser estabelecida pela mediação do lembrar, por um processo meditativo e reflexivo que estabelece uma nova relação entre o passado e o presente. Essa relação ao mesmo tempo singular e significativa que obriga o passado a estabelecer novas

Cadernos Benjaminianos, n. 3, Belo Horizonte, jan.-jun. 2011, p.14-25 
significações com o presente é o que WB chama de rememoração. "Articular historicamente o passado não significa conhecê-lo 'tal como ele propriamente foi'. Significa apoderar-se de uma lembrança tal como ela cintila num instante de perigo". ${ }^{41}$

\section{Rememoração}

A rememoração (Eingedenken) surge nas teses Sobre o conceito de história como o retorno cíclico dos dias festivos, que sempre e de novo reúne passado e presente em torno de um acontecimento. "No fundo, é o mesmo dia que retorna sempre na figura dos dias de festa, que são os dias da rememoração". Esse movimento de restauração que é também abertura para o novo, para uma nova confrontação com o mundo histórico, faz da rememoração um procedimento oposto ao modelo tradicional do historicismo de postular um fato histórico positivo e de impor à história sua lógica de causa e efeito. ${ }^{43}$

Eigedenken, portanto, não significa simplesmente evocar, isoladamente, a lembrança de um passado, esquecendo-se do próprio presente ou, como Foustel de Coulanges postula, esquecendo-se de 'tudo o que se sabe sobre fases posteriores da história' ( $7^{\mathrm{a}}$ tese). Não se trata de conservar o passado num esforço museal de memória, mas de relacioná-lo diretamente com o presente e de reanimá-lo do mesmo modo que o anjo da $9^{\text {a }}$ tese quer devolver a vida aos mortos. ${ }^{44}$

A rememoração integra e sobrepõe, portanto, épocas distantes e aparentemente desconectadas e assim, por um lado, supera o isolamento da distância temporal ao juntar as ruínas da história nessa espécie de tempo absoluto, sem amarras e, por outro, constrange passado e presente a estabelecerem uma nova conexão significativa que não pode ser reduzida a uma continuidade linear. A rememoração, portanto, é uma espécie de "citação" histórica que extrai significados da junção de épocas às vezes separadas por milênios. "Assim, a Roma antiga era para Robespierre um passado carregado de temposde-agora (Jetztzeit) que ele fazia explodir do continuum da história. A Revolução Francesa compreendia-se como uma Roma retornada. Ela citava a Roma antiga exatamente como a moda cita um traje do passado". ${ }^{45} \mathrm{O}$ historiador, portanto, é condenado ao relativo, ao parcial, às ruínas do passado que, "analisadas à luz de um presente em mudança contínua, formam uma 'constelação' sempre diferente". ${ }^{46}$ Como fugir, então, a um relativismo em termos do conhecimento histórico? A influência de Schlegel e dos românticos de Iena é aqui decisiva: pensar uma esfera de neutralidade em relação aos conceitos de sujeito e objeto é reconquistar a dimensão em que o mundo é dado em sua plena significação por estar em união com o sujeito. Assim sendo, cada experiência particular de um indivíduo reaparece como um fragmento significativo que, se recuperado pelo esforço do rememorar, é colocado juntamente aos inúmeros outros fragmentos para que, no jogo de conexões, a verdade de uma determinada época possa se apresentar. Nesse sentido, a ideia que se apresenta na história como origem é capaz de constituir uma imagem abreviada do mundo e de espelhá-lo pelo fato mesmo de que o que se espelha, em última instância, é a unificação de eu e mundo, i.e., o resgate da dimensão significativa do conhecimento para o qual a distinção de sujeito e objeto deixa de fazer sentido.

Cadernos Benjaminianos, n. 3, Belo Horizonte, jan.-jun. 2011, p.14-25 
Abstract: This paper intends to indicate, in the first place, that Walter Benjamin's interest in the problem of history was already present in his earlierst writings and was since then connected to an essentialy epistemological investigation. In the second place, it aims to show how this early epistemology could contribute to the understanding of the late work On the concept of history, highlighting remembrance (Eingedeken) as a key-concept to this approach.

Keywords: refletion; origin; remembrace.

\section{Referências Bibliográficas}

BENJAMIN, Andrew; OSBORNE, Peter. Walter WB's Philosophy. Destruction and Experience. London and New York: Routledge, 1994.

BENJAMIN, W., Gesammelte Schriften. Herausgegeben von Rolf Tiedemann und Hermann Schweppenhäuser. Frankfurt am Main: Suhrkamp, 1972-1985; v. I- 1, 2; v. II1,2 , v. IV-1; v. VI.

- On the mimetic faculty. Tradução de Edmund Jephcott, Editora Schocken

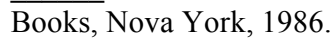

- O conceito de crítica de arte no romantismo alemão. Tradução Márcio Seligmann-Silva. São Paulo: Iluminuras, 1993.

. Gesammelte Briefe Band I (1910-1918). Christoph Gödde e Henri Lonitz (Hrsg.) Frankfurt a.M.: Suhrkamp Verlag, 1995.

. Selected Writings Vol. I, 1913-1926. Edited by Marcus Bullock and Michael W. Jennings. London: Harvard University Press, 1996. \& Alvin, 2004

. Origem do drama trágico alemão. Tradução João Barrento. Lisboa: Assírio

. "Teses sobre o conceito de história". In: LÖWY, Michael. Walter WB: aviso de incêndio: uma leitura das teses "Sobre o conceito de história". Tradução das teses de Jeanne-Marie Gagnebin. São Paulo: Boitempo, 2005.

GAGNEBIN, Jeanne-Marie. História e narração em Walter WB. São Paulo: Perspectiva, 1994.

. Do conceito de Darstellung em Walter WB ou verdade e beleza. En Revista Kriterion, Belo Horizonte, v. 46, n. 112, Dec. 2005.

. "Über den Begriff der Geschichte" von J-M.G. En: LINDNER, Burkhardt; KÜPPER, Thomas; SKRANDIES, Timo. WB-Handbuch: Leben, Werk, Wirkung. Stuttgart; Weimar: Verlag J.B. Metzler, 2006.

. Nas fontes paradoxais da crítica literária. Walter WB relê os românticos de Iena. En Seligmann-Silva, Márcio (org.) Leituras de Walter WB, São Paulo, Anna Blume, Fapesp, 2007.

- Da escrita filosófica em Walter WB. En Seligmann-Silva, Márcio (org.)

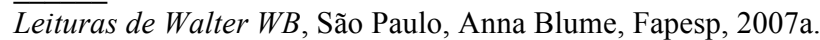

Cadernos Benjaminianos, n. 3, Belo Horizonte, jan.-jun. 2011, p.14-25 
"Documentos de cultura/documentos de barbárie". In: IDE Revista de

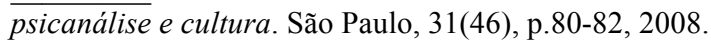
p.39-44, jan.2008a.

“A questão do 'Eros' na obra de WB”. In: Artefilosofia. Ouro Preto, n.4,

KANT, I. Kritik der Urteilskraft. Herausgegeben von Heiner Klemme. Hamburgo: Felix Meiner, 2006 (1790) mit Beilage: Erste Einleitung in die Kritik der Urteilskraft.

Iluminuras, 1995.

Duas introduções à Crítica do Juízo. Trad. Ricardo Terra, São Paulo:

. Crítica da Faculdade do Juízo. Trad. Valério Rohden e António Marques. 2.Ed. Rio de Janeiro: Forense Universitária, 2005.

MARQUES, Antonio. "O valor crítico do conceito de reflexão em Kant" in Studia Kantiana, vol. 4, n.1, Nov.2002 - p. 43-60.

MOLDER, Maria Filomena. Método é desvio. Uma experiência de limiar. OTTE, Georg; et. al. (orgs). Limiares e passagens em Walter Benjamin. Belo Horizonte: Editora UFMG, 2010

MURICY, Katia. Alegorias da Dialética: imagem e pensamento em Walter WB. Rio de Janeiro: Nau Editora, 2009.

OTTE, Georg. Rememoração e Citação em Walter Benjamin. Revista de estudos de literatura. Belo Horizonte, v.4, p. 211-213, outubro 1996.

OTTE, Georg; et. al. (orgs). Limiares e passagens em Walter Benjamin. Belo Horizonte: Editora UFMG, 2010.

SELIGMANN-SILVA, Márcio. Ler o livro do mundo. Walter WB: romantismo e critica poética. São Paulo: FAPESP: Iluminuras, 1999.

SUZUKI, Márcio. O gênio romântico: Crítica e história da filosofia em Friedrich Schlegel. São Paulo: Iluminuras e FAPESP, 1998.

SWEPPENHÄUSER, Hermann, Praesentia praeteritorum. $\mathrm{Zu}$ Benjamins Geschichtsbegriff. In BULTHAUPT, Peter (Hrsg). Materialen zu Benjamins Thesen „Über den Begriff der Geschichte“. Beiträge und Interpretationen. Frankfurt am Main: Suhrkamp Verlag, 1975.

\section{Notas}

${ }^{1}$ Benjamin se dedica principalmente à "Crítica da razão pura", à "Crítica da faculdade de julgar" e à "Fundamentação da metafísica dos costumes". Cf. Chronology in WB, 1996, p. 490-515.

WB, GS II, 1, p. 157

${ }^{3}$ Id., p. 159

${ }^{4}$ Id., p. 161

${ }^{5}$ WB, 1996, p.276 [Erkenntnistheorie]

${ }^{6}$ Id., ibdi.

${ }^{7}$ Gesammelte Briefe Band I, p. 441

${ }^{8}$ Ibid., p.486

${ }^{9}$ GS, I-1 p.11

${ }^{10}$ Id., p.56 
${ }^{11}$ Id., p.35

${ }^{12}$ Cf. GS I, 1 Die Bedeutung der Reflexion bei den Frühromantikern, p. 26-40.

${ }^{13}$ Op. cit. Ver também o artigo de MOLDER, 2010, p. 27-75.

${ }^{14} \mathrm{Com}$ efeito, é na Terceira Crítica que Kant trata da possibilidade do ajuizamento de representações singularíssimas, para as quais não se pode determinar conceito algum e que se referem inteiramente ao 'sentimento' ou ao 'estado interno' (Gemütszustand) do sujeito frente à representação do objeto. Cf. Duas introduções à critica do juízo, 1995.

${ }^{15}$ GS, I-1, p.26

${ }^{16}$ No sistema de fragmentos romântico, "a totalidade é aceita como um a priori." O fragmento só existe como parte de um todo, o qual não pode ser completamente determinado. "Uma sistematicidade enquanto fim: agente de estruturação mas que nunca é alcançado." Cf. SELIGMANN-SILVA, 1999, p.50.

${ }^{17}$ GS II-1, p. 170 - Grifos meus

${ }^{18}$ Considerado expoente de uma época mais marcadamente místico-teológica de WB, esse texto (Über Sprache überhaupt und über die Sprache des Menschen, GS II-1, p.140157) lança mão de uma leitura muito própria do Gênese, em que o homem é pensado "à imagem e semelhança de Deus" em função da dimensão propriamente criadora da linguagem, em que o ato de nomear faz com que a essência da coisa nomeada se expresse de maneira imediata no nome. Esse recurso ao relato bíblico, no entanto, não serve ao intento de pensar uma situação originária de harmonia mas, tão somente, ao intento de pensar a linguagem em sua dimensão essencialmente significativa, em detrimento da leitura que a subordina ao aspecto meramente comunicativo.

19 Cf. MURICY, 2009, principalmente o capítulo I, intitulado "A metafísica da juventude".

${ }^{20}$ Como muito bem fundamentado por Márcio Seligmann-Silva, 1999, p.23 seq.

${ }^{21}$ SELIGMANN-SILVA, 1999, p.24

${ }^{22} \mathrm{O}$ termo em alemão é "künstliche Sprache", no qual o adjetivo "künstlich", derivado de "Kunst", pode ser entendido tanto como "artificial" quanto como "artístico".

${ }^{23}$ GS II-1, p. 141

${ }^{24}$ GAGNEBIN, 2007a, p. 88

${ }^{25}$ Título de uma revista literária fundada pelos irmãos Schlegel em 1798.

${ }^{26}$ apud GS I-1, p.44

${ }^{27}$ WB, SW, 1996, p.278-279

${ }^{28}$ Id., ibdi.

${ }^{29}$ GS I-1, p.209.

${ }^{30}$ Id., p. 214

${ }^{31}$ Id., p. 208

${ }^{32}$ Id., p. 216

${ }^{33}$ MOLDER, Maria Filomena, op.cit. p. 44-45.

${ }^{34}$ WB, SW, 1986, p.334

${ }^{35}$ Para o uso do conceito de virtualidade neste contexto, Cf. WEBER, Samuel, 2008.

${ }^{36}$ GS I-1, p.226. Os termos em alemão são Vorgeschichte e Nachgeschichte, e aqui a tradução foi modificada de "pré e pós-história" para "história anterior" e "história posterior" para ressaltar a diferença conceitual entre Nachgeschichte e Posthistorie (mais diretamente "pós-história", termo conceitualizado no debate da estética contemporânea por autores como, por exemplo, Arthur Danto e Vilém Flusser).

${ }^{37}$ GAGNEBIN, 1994, p.14

${ }^{38}$ Id., p. 11

${ }^{39}$ Id., p. 14

${ }^{40}$ GAGNEBIN, 2006, p. 42

${ }^{41}$ GS I-2, p.696

${ }^{42}$ Id. p. 699 
${ }^{43}$ Cf. OTTE, 1996, p. 213. "Fruto do Positivismo do século XIX, o Historicismo procura restringir o trabalho do historiador à detecção do fato puro (positivo), querendo evitar a adoção de uma lógica que estabeleça uma ligação entre estes fatos e que dê um sentido à história."

${ }^{44}$ OTTE, 1996, p. 214

${ }^{45}$ GS I-2, p. 698. Cf. OTTE, 1996, p.219. "Levando-se em conta o fator do tempo e a distância temporal entre os textos, pode-se dizer que cada texto desta totalidade repete, de alguma forma, um texto anterior e que a citação é apenas a explicitação de uma das muitas conexões possíveis que evidenciam as afinidades intertextuais."

${ }^{46}$ OTTE, op.cit. 